\title{
Morphological Study of Polymer Blend of Poly(acrylic acid) and Polystyrene by Inverse Gas Chromatography
}

\author{
Yoshimasa Murakami,* Tomoyuki InUI, Toshimitsu SuZUKI, \\ and Yoshinobu TAKEGAMI \\ Department of Hydrocarbon Chemistry, Faculty of Engineering, \\ Kyoto University, Kyoto 606, Japan
}

(Received October, 25, 1982)

\begin{abstract}
The surface structure of a polymer blend of poly(acrylic acid) (PAA) and polystyrene (PS) was investigated by means of inverse gas chromatography (IGC) and scanning electron microscopy (SEM). The following morphological changes were found: The PAA and PS domains form the sea and island phases, respectively, regardless of the composition. The size of the PS domain greatly increases in the range from ca. 30 to ca. $50 \mathrm{wt} \%$ PS. At $c a .60 \mathrm{wt} \%$ PS, the PS domain becomes small in size and is dispersed on the PAA domain, and protrudes from the PAA domain in a ball-like shape. Above $c a .75 \mathrm{wt} \%$ PS, the ball-like PS domains are aggregated and spread over the surface of the PAA domain. However, the PS domain does not completely cover the PAA domain and leaves some vacant spaces. The surface structure undergoes no great change by thermal treatment below $c a .50 \mathrm{wt} \%$ PS. Above $c a .60 \mathrm{wt} \%$ PS, the ball-like PS domain is melted by thermal treatment and spreads over the PAA domain. The change in the surface area of a polymer blend by thermal treatment can be estimated from the difference in retention volume of the first and second measurements carried out using the same column.
\end{abstract}

KEY WORDS Inverse Gas Chromatography / Scanning Electron Microscopy / Polymer Blend / Poly(acrylic acid) / Polystyrene / Morphology / Phase Separation / Surface Area / Thermal Treatment /

Inverse gas chromatography (IGC), a useful method for investigating the physical properties of polymers such as glass transition temperature $\left(T_{\mathrm{g}}\right)$ or melting temperature $\left(T_{\mathrm{m}}\right),{ }^{1-5}$ has recently been found useful for characterizing multicomponent polymer systems such as copolymers and polymer blends. $^{6-12}$

In our previous work, ${ }^{11}$ we applied IGC to a morphological study of a polymer blend of poly(ethylene oxide) (PEO) and polystyrene (PS) (PEO-PS blend). The two Z-shaped curves observed around the $T_{\mathrm{g}}$ of PS and the $T_{\mathrm{m}}$ of PEO were distinctly separated from each other in the retention diagram (RD) of IGC. The Z-shaped curve around the $T_{\mathrm{m}}$ of PEO changed sensitively with the composition, while little change occurred in the Zshaped curve around the $T_{\mathrm{g}}$ of PS. These results enabled us to investigate the surface structure of a PEO-PS blend by IGC. However, in order to extend this method for a wide variety of polymer blends, it is necessary to examine whether IGC permits morphological study of binary polymer blends in which the component polymers do not have melt transition but have glass transition in the temperature range of usual measurement (40$180^{\circ} \mathrm{C}$ ) and the two Z-shaped curves are not sufficiently separated from each other in RD.

In this work, we investigated the surface structure of a polymer blend of poly(acrylic acid) (PAA, $\left.T_{\mathrm{g}} \simeq 120^{\circ} \mathrm{C}\right)$ and PS $\left(T_{\mathrm{g}} \simeq 95^{\circ} \mathrm{C}\right)$ (PAA-PS blend) using IGC and a scanning electron microscope (SEM). The morphological study of a PAA-PS blend is of interest since this blend consists of hydrophilic and hydrophobic polymers differing from a PEO-PS blend.

\section{EXPERIMENTAL}

\section{Materials}

Wako Pure Chemical's PS $\left(M_{n}=1.8 \times 10^{5}\right)$ was 
purified by dissolving in benzene and precipitating into methanol followed by freeze-drying from a benzene solution under vacuum. Wako Pure Chemical's PAA $\left(M_{n}=9.0 \times 10^{4}\right)$ was also freezedried from an aqueous solution under vacuum. $N, N$-Dimethylformamide (DMF), a mutual solvent for these two polymers, was used to deposit the polymer mixture on a porous support. Since a clear Z-shaped RD had been obtained using silanetreated Chromosorb, ${ }^{13}$ Chromosorb P AW-DMCS 60-80 mesh (Johns-Manville Co.) was also employed in this study as the porous support for the column of gas chromatography. $n$-Decane was used as the solute. Trimethylchlorosilane and hexamethyldisilazane were used for silane-treatment of the glass plate surface on which a polymer film was cast from a DMF solution for SEM observation.

\section{Columns}

The columns prepared in this series of experiments are summarized in Table I. A calculated amount of a PAA-PS mixture was dissolved in DMF $\left(2.5 \mathrm{w} / \mathrm{v} \%\right.$, at $\left.80^{\circ} \mathrm{C}\right)$ and the Chromosorb was added. The solvent was allowed to evaporate at $80^{\circ} \mathrm{C}$ by gentle and continuous stirring of the solution followed by drying at $60^{\circ} \mathrm{C}$ under reduced pressure. The loaded polymer weight $(\mathrm{wt} \%$ ) was calculated from the weight increase of the Chromosorb support. A weighed amount of the polymer-loaded Chromosorb was tightly packed into a $1.5 \mathrm{~m} \times 3 \mathrm{~mm}$ i.d. stainless steel column. The

Table I. Gas chromatographic columns

\begin{tabular}{crrrr}
\hline \multirow{2}{*}{$\begin{array}{c}\text { Column } \\
\text { No. }\end{array}$} & \multicolumn{2}{c}{ PS } & & Polymer loading \\
\cline { 2 - 3 } & $\mathrm{wt}^{\mathrm{c}} \mathrm{o}^{\mathrm{a}}$ & $\mathrm{mol} \% \mathrm{~b}$ & & $\mathrm{wt} \%$ \\
\hline 1 & 100 & 100 & & 9.9 \\
2 & 83 & 78 & & 10.0 \\
3 & 75 & 67 & & 9.8 \\
4 & 67 & 58 & & 10.0 \\
5 & 60 & 51 & & 10.0 \\
6 & 50 & 40 & & 10.0 \\
7 & 33 & 26 & & 9.9 \\
8 & 0 & 0 & 10.0 \\
\hline
\end{tabular}

a $\operatorname{PS}(\mathrm{g}) /[\mathrm{PS}(\mathrm{g})+\mathrm{PAA}(\mathrm{g})] \times 100$.

b Calculated in terms of monomer units.

c Calculated from the weight of the whole polymer loaded. column was dried for $5 \mathrm{~h}$ at $60^{\circ} \mathrm{C}$ under a constant stream of helium.

\section{Gas Chromatography}

Gas chromatograms were recorded on a Yanaco G 1800 equipped with a thermal conductivity detector, using helium as the carrier gas and air as a noninteracting marker. In all measurements, the flow rate and injection temperature were fixed at $20 \mathrm{ml} \mathrm{min}{ }^{-1}$ and $100^{\circ} \mathrm{C}$, respectively. Air $(0.4 \mu \mathrm{l})$ and $n$-decane $(0.6 \mu \mathrm{l})$ were injected simultaneously. The net retention volume $V_{\mathrm{N}}(\mathrm{ml})$ from the air peak to the front side of the solute peak was measured. The specific retention volume $V_{\mathrm{g}}\left(\mathrm{ml} \mathrm{g}^{-1}\right)$ was calculated from the equation $V_{\mathrm{g}}=V_{\mathrm{N}} / w$, where $w$ is the loaded polymer weight $(g) .{ }^{11,14}$ For each column, measurement was carried out by raising the column temperature $T(\mathrm{~K})$ from 333 to $453 \mathrm{~K}$. The retention diagrams (RDs) were obtained by plotting $\log V_{\mathrm{g}}$ against $10^{3} / T$. The second measurement using the same column was carried out several days after the first measurement in order to investigate the effect of thermal treatment on the surface structure of the PAA-PS blends.

\section{Scanning Electron Microscopy}

SEM photographs were obtained on a HitachiAkashi MSM4C-102 operated at $30 \mathrm{kV}$. The polymer was cast onto a silane-treated glass plate from a DMF solution. In some cases, the polymer film on the glass plate was maintained at $180^{\circ} \mathrm{C}$ for $3 \mathrm{~h}$ under a constant stream of helium. The samples were coated with $200 \AA$ of gold, and SEM observations were made in a magnification range from 1000 to 5000 by varying the beam angle from 0 to $45^{\circ}$.

\section{RESULTS AND DISCUSSION}

\section{Influence of the Composition on the Retention Diagram}

Figure 1 shows the RDs from the first heating-up measurements for columns prepared at various compositions. In the RD for column NO. 1 $(100 \mathrm{wt} \% \mathrm{PS})$, the Z-shaped curve due to the glass transition of PS was observed around $95^{\circ} \mathrm{C}$. In the RD for column No. $8(0 \mathrm{wt} \%$ PS, i.e., $100 \mathrm{wt} \%$ PAA) the Z-shaped curve due to the glass transition of PAA was observed only less clearly around $120^{\circ} \mathrm{C}$. Two Z-shaped curves could be seen around 


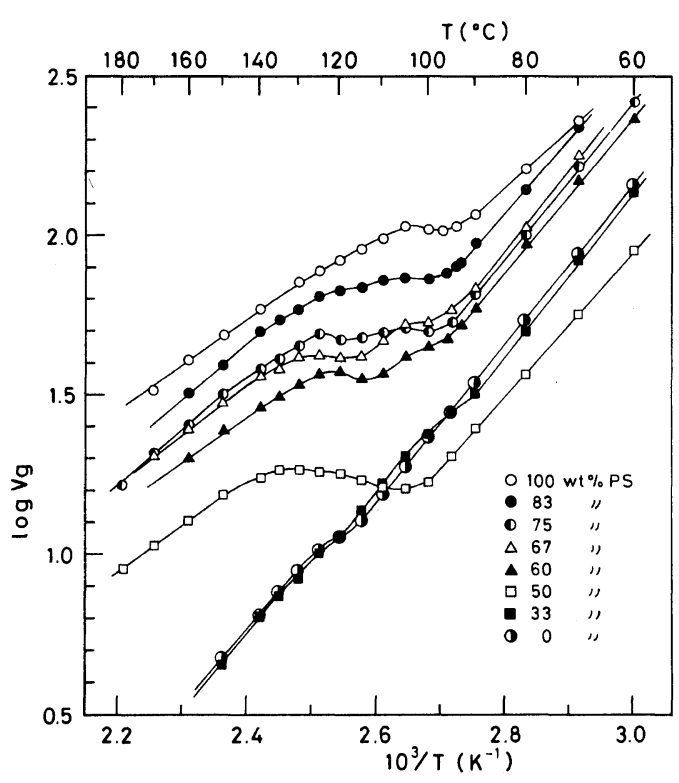

Figure 1. Effect of composition on the retention diagram for $n$-decane on PAA-PS blend: The first measurement, (O) column No. $1(100 \mathrm{wt} \%$ PS); (O) No. 2 (83wt $\%$ PS); (D) No. 3 (75 wt $\%$ PS); $(\triangle)$ No. 4

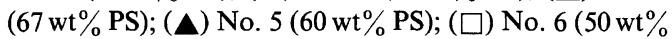

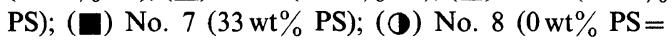
$100 \mathrm{wt} \%$ PAA).

95 and $120^{\circ} \mathrm{C}$ in the RDs for columns No. 2-7, indicating that, when mixed, PAA and PS undergo phase separation regardless of the composition. PAA and PS have no common organic solvents except DMF. This fact may be related to the finding that PAA and PS are incompatible.

The RD for column No. 7 (33 wt $\%$ PS) almost overlapped with that for column No. $8(0 \mathrm{wt} \%$ PS), and the Z-shaped curve around the $T_{\mathrm{g}}$ of PS was less clear. These results suggest that, at $33 \mathrm{wt} \% \mathrm{PS}$, the PS domain is fairly small compared to the PAA domain and the surface structure is almost identical with that of PAA.

That RD greatly changed in the range of PS composition from 33 to $50 \mathrm{wt} \%$ indicates that the surface structure of a PAA-PS blend undergoes appreciable change in this composition range. In the RD for column No. $6(50 \mathrm{wt} \%$ PS) the Z-shaped curve due to the glass transition of PS was fairly clear, indicating a great increase in the surface area of the PS domain.

The RD for column No. $5(60 \mathrm{wt} \%$ PS) shifted upward from that for column No. 6 and exhibited two Z-shaped curves clearly. Therefore, it may be considered that the surface structure of a PAA-PS blend greatly changes in the range from 50 to $60 \mathrm{wt} \%$ PS.

Above $60 \mathrm{wt} \%$ PS, the RD underwent no essential change and gradually approached that for column No. $1(100 \mathrm{wt} \%$ PS) with increasing PS content. This indicates that the surface structure of a PAA-PS blend above $60 \mathrm{wt} \%$ PS changes in proportion to PS content. Two Z-shaped curves still appeared in the RD for column No. 2 (83 wt \% PS), implying that the PAA domain is not covered with the PS domain even at $83 \mathrm{wt} \% \mathrm{PS}$.

\section{SEM Photographs of PAA-PS Blend}

The SEM photographs of cast films of PAA-PS blends prepared at various compositions are given in Figure 2. Phase separation was observed in each photograph. Since the average area of the island phase increased with an increase in PS content, the PS domain was considered to be the island phase.

Photograph (a) (33 wt \% PS) shows the very small island phases of the PS domain and the sea phase of the PAA domain, indicating that the surface structure is essentially the same as that of PAA alone. The average size of the PS domain appeared too small for its content $(33 \mathrm{wt} \%)$. This may be due to the considerably small thickness of the PAA domain compared to that of the PS domain, which may be accounted for by the good wettability of PAA on the glass surface. A great increase in the size of the PS domain can be seen in photograph (b) ( $50 \mathrm{wt} \% \mathrm{PS}$ ); the PS domain is greatly spread out in the range from 33 to $50 \mathrm{wt} \%$ PS. At $60 \mathrm{wt} \%$ PS [photograph (c)], however, the PS domain is dispersed on the PAA domain and its size is smaller than that in photograph (b). Further, the PS domain protrudes from the PAA domain as a ball-like shape. The ball-like PS domains are aggregated and spread over the surface of the PAA domain at $75 \mathrm{wt} \%$ PS [photograph (d)]. The surface of the polymer film prepared at $83 \mathrm{wt} \%$ PS [photograph (e)] looks almost like that of PS alone [photograph (f)]. The surface of PS film cast from DMF looks like an aggregate of ball-like polymers and has some vacant spaces. Even at $83 \mathrm{wt} \%$ PS, therefore, the PAA domain was not completely covered with the PS domain, suggesting the occurrence of an interaction between PAA and the solute molecule. 

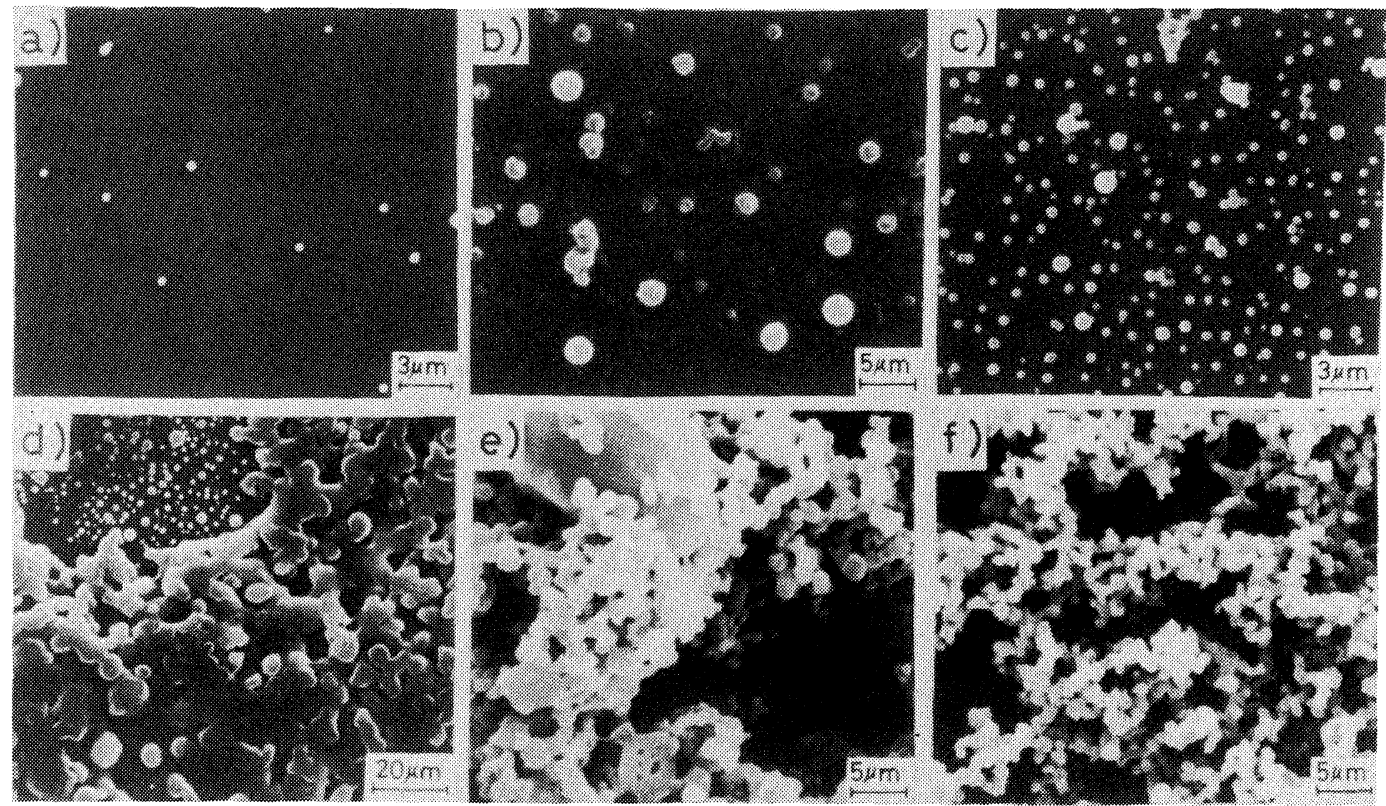

Figure 2. SEM photographs of PAA-PS blends cast from DMF: Before thermal treatment, wt $\%$ PS, (a) 33; (b) 50; (c) 60; (d) 75; (e) 83; (f) 100 .
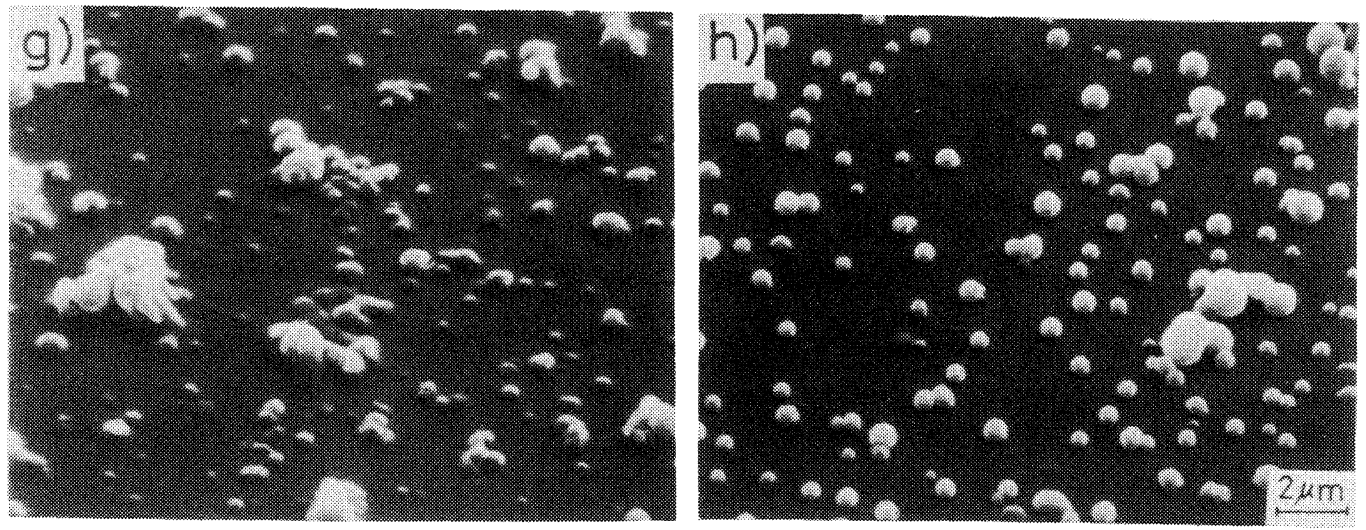

Figure 3. SEM photographs of PAA-PS blends cast from DMF: Before thermal treatment, beam angle, $45^{\circ} ; \mathrm{wt} \%$ PS, (g) 50; (h) 60 .

Figure 3 shows the SEM photographs of PAAPS blends measured at a beam angle of $45^{\circ}$. The surface of the PS domain slightly protrudes above the PAA domain at $50 \mathrm{wt} \%$ PS [photograph (g)], while the ball-like PS domain almost rises to the surface of the PAA domain at $60 \mathrm{wt} \%$ PS [photograph (h)].

These SEM results agree very closely with the morphological consideration from the IGC results. Therefore, it may be concluded that IGC is a very simple and good technique for studying the morphology of polymer blends.

The morphological features of PAA-PS blends were found to be different from those of PEO-PS blends. In PEO-PS blends, the sea-island phase inversion occurred around $50 \mathrm{wt} \% \mathrm{PS}$ and the PEO 
domain was completely covered with the PS domain above $80 \mathrm{wt}^{\circ} \%$ PS. $^{11}$

\section{Effect of Thermal Treatment on the Surface Structure of PAA-PS Blend}

Figure 4 shows the RDs from the second heatingup measurements (RDs-2nd). The RD-2nd for col-

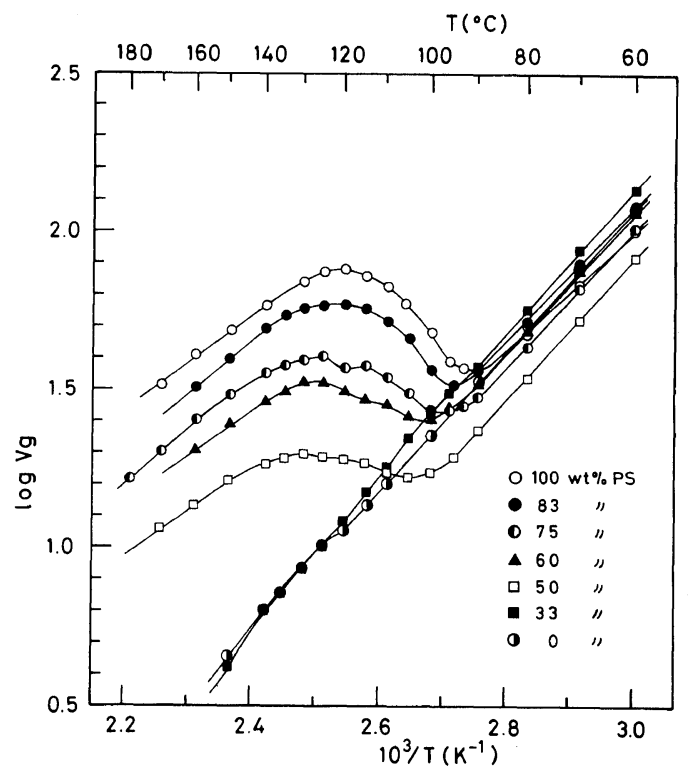

Figure 4. Effect of composition on the retention diagram for $n$-decane on PAA-PS blend: The second measurement, (O) column No. 1 (100 wt \% PS); (○) No. 2 (83wt \% PS); (D) No. 3 (75 wt $\%$ PS); (A) No. 5

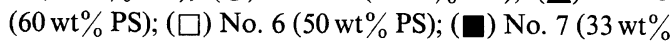
PS); () No. 8 (0 $\mathrm{wt}_{\%} \%$ PS).

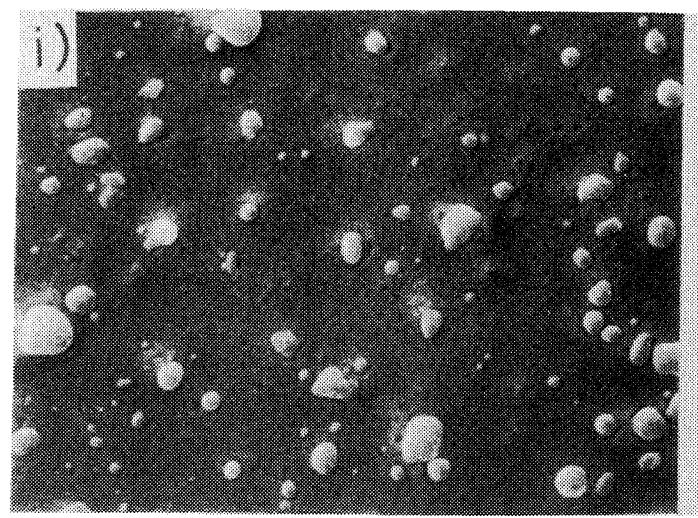

umn No. 8 (100 wt \% PAA) was almost the same as the RD from the first heating-up measurement (RD-1st), suggesting that the surface structure of PAA is scarcely affected by thermal treatment. On the other hand, the Z-shaped curve in the RD-2nd for column No. 1 (100 wt \% PS) was considerably clearer than that in the RD-1st, i.e., the value of $\log V_{\mathrm{g}}$ in the RD-2nd was quite smaller than that in the RD-1st below the $T_{\mathrm{g}}$ of PS.

In general, the retention of a solute is caused exclusively by surface adsorption below the $T_{\mathrm{g}}$ of a polymer, and above this, the penetration of the solute into the bulk of the polymer (bulk sorption) begins in the amorphous domain. ${ }^{5}$ The decrease in $\log V_{\mathrm{g}}$ below the $T_{\mathrm{g}}$ of PS indicates a decrease in the amount of surface adsorption, viz., a decrease in the surface area of the PS domain. Since the amount of polymer bulk does not change by thermal treatment, the values of $\log V_{\mathrm{g}}$ in the RD-2nd were the same as those in the RD-1st in the equilibrium region of bulk sorption (above $130^{\circ} \mathrm{C}$ ).

The RDs-2nd for columns No. 6 and 7 almost overlapped with the corresponding RDs-1st. Therefore, it may be considered that below $50 \mathrm{wt} \%$ PS the surface structure does not greatly change by thermal treatment. In the RDs-2nd for columns No. 2,3 , and 5, the Z-shaped curves around $95^{\circ} \mathrm{C}$ became much clearer than in the corresponding RDs-1st, i.e., the surface areas of the PS domains decreased by thermal treatment.

In Figures 5 and 6 are shown the SEM photographs of thermally treated films of PAA-PS blends. Comparison of Figures 2 and 3 with 5

Figure 5. SEM photographs of PAA-PS blends cast from DMF: After thermal treatment, wt $\%$ PS, (i) 50; (j) 60 . 

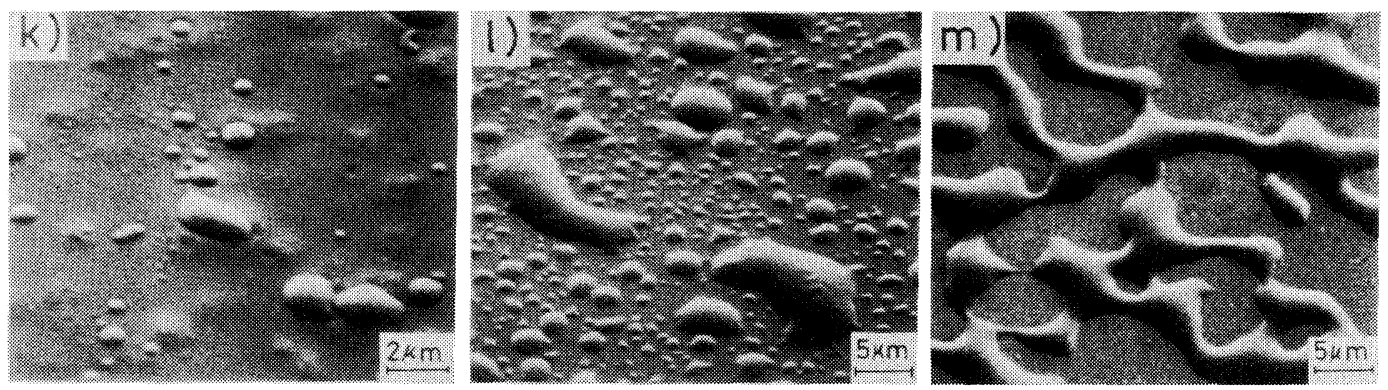

Figure 6. SEM photographs of PAA-PS blends cast from DMF: After thermal treatment, beam angle, $45^{\circ}$; wt $\%$ PS, (k) 50; (l) 60; (m) 100 .

Table II. Values of $\Delta \log V_{\mathrm{g}}$ and $S_{\mathrm{b}} / S_{\mathrm{a}}$

\begin{tabular}{|c|c|c|c|c|}
\hline \multirow{2}{*}{$\begin{array}{c}\text { Column } \\
\text { No. }\end{array}$} & PS content & $\begin{array}{l}\text { Weight of PS } \\
\text { in column }\end{array}$ & \multirow{2}{*}{$\Delta \log V_{\mathrm{g}}^{\mathrm{a}}$} & \multirow{2}{*}{$S_{\mathrm{b}} / S_{\mathrm{a}}^{\mathrm{b}}$} \\
\hline & $w t \%$ & g & & \\
\hline 1 & 100 & 0.54 & 0.53 & 8.0 \\
\hline 2 & 83 & 0.44 & 0.42 & 6.5 \\
\hline 3 & 75 & 0.37 & 0.36 & 5.5 \\
\hline 4 & 67 & 0.33 & 0.35 & 5.0 \\
\hline 5 & 60 & 0.30 & 0.27 & 4.0 \\
\hline 6 & 50 & 0.25 & 0.03 & 1.0 \\
\hline
\end{tabular}

a The difference in $\log V_{\mathrm{g}}$ at $80^{\circ} \mathrm{C}$ between the first and second measurements.

b $S_{\mathrm{a}}$ and $S_{\mathrm{b}}$ designate surface areas of PAA-PS blends in the column after and before thermal treatment, respectively.

and 6 shows that the surface structure of the film prepared at $50 \mathrm{wt} \%$ PS undergoes no great change with thermal treatment, whereas the ball-like PS domains are melted by thermal treatment and spread out in the films prepared at 60 and 100 $\mathrm{wt} \%$ PS. These observations agree well with the findings from IGC measurements.

Since retention is exclusively due to surface adsorption below the $T_{\mathrm{g}}$ of PS, the difference in $\log V_{\mathrm{g}}$ at $80^{\circ} \mathrm{C}$ between the first and second measurements $\left(\Delta \log V_{\mathrm{g}}\right)$ may be taken as a measure of the difference in the surface areas of PAA-PS blends before and after thermal treatment $\left(S_{\mathrm{b}} / S_{\mathrm{a}}: S_{\mathrm{a}}\right.$ and $S_{\mathrm{b}}$ designate the total surface areas of the polymer blends in the column after and before thermal treatment, respectively). The relation between $\Delta \log V_{\mathrm{g}}$ and $S_{\mathrm{b}} / S_{\mathrm{a}}$ for each column were calculated going on the following assumptions: the average diameter of PS balls before thermal treatment is $0.5 \mu \mathrm{m}$ at any composition; the PS domains after thermal treatment can be regarded as aggregates of hemispheres; the average diameter of the hemispheres is $2 \mu \mathrm{m}$ at $60 \mathrm{wt} \% \mathrm{PS}$, and $4 \mu \mathrm{m}$ at $67-$ $100 \mathrm{wt} \%$ PS; the surface area of the PAA domain does not change by thermal treatment. As can be seen from Table II, $\Delta \log V_{\mathbf{g}}$ is approximately proportional to $S_{\mathrm{b}} / S_{\mathrm{a}}$ above $60 \mathrm{wt} \%$ PS. Therefore, the degree of decrease in the surface area of a PAA-PS blend on Chromosorb can be estimated by the value of $\Delta \log V_{\mathrm{g}}$. This result suggests that IGC can be a useful method for measuring the surface area of homopolymer and multicomponent polymer systems.

\section{REFERENCES}

1. O. Smidsrød and J. E. Guillet, Macromolecules, 2, 272 (1969).

2. A. Lavoie and J. E. Guillet, Macromolecules, 2, 443 (1969).

3. J. E. Guillet and A. N. Stein, Macromolecules, 3, 102 (1970).

4. J.-M. Braun, A. Lavoie, and J. E. Guillet, Macromolecules, 8, 311 (1975).

5. J.-M. Braun and J. E. Guillet, Adv. Polym. Sci., 21, 107 (1976).

6. K. Ito, H. Sakakura, and Y. Yamashita, J. Polym. Sci., Polym. Lett. Ed., 15, 755 (1977).

7. K. Ito, H. Sakakura, K. Isogai, and Y. Yamashita, $J$. Polym. Sci., Polym. Lett. Ed., 16, 21 (1978).

8. M. Galin and M. C. Rupprecht, Macromolecules, 12, 506 (1979).

9. K. Ito, N. Usami, and Y. Yamashita, Macromolecules, 13, 216 (1980).

10. G. DiPaola-Baranyi, Polym. Prep., Am. Chem. Soc., Div. Polym. Chem., 21(2), 214 (1980). 
11. T. Suzuki, Y. Murakami, T. Inui, and Y. Takegami, Polym. J., 13, 1027 (1981).

12. T. Inui, Y. Murakami, T. Suzuki, O. Yamada, and Y. Takegami, Macromolecules, under contribution.
13. T. Inui, Y. Murakami, T. Suzuki, and Y. Takegami, Polym. J., 14, 261 (1982).

14. J.-M. Braun and J. E. Guillet, Macromolecules, 8, 882 (1975). 